\title{
Studies Related to Dyslexia in Chinese Characters
}

\author{
Jin Jing, Guifeng $\mathrm{Xu}$, Xiuhong Li and $\mathrm{Xu}$ Huang \\ Sun Yat-sen University, \\ China
}

\section{Introduction}

Dyslexia usually refers to a series of difficulties with reading even though patients have normal intelligence, affection, availability of education and social and cultural chances. In western children whose mother tongue is alphabetic, the rate of dyslexia is $5 \% \sim 10 \%{ }^{[1]}$ while the rate is supposed to be $4 \% \sim 8 \%$ in China..[2] Chinese characters are a special semantic language, which are very different from alphabetic languages. First, most Chinese characters consist of two parts: the one usually indicates meaning, while the other one usually indicates pronunciation. Second, some Chinese characters originate from ancient simple pictures in China. Besides, China is a big country with the most children in the world, and there are increasing numbers of studies concerned specifically with dyslexia in Chinese characters.

\section{The subtypes of dyslexia in Chinese characters}

There are two major classifications of dyslexia in alphabetical languages (e.g. English). One was proposed by Castle,[3] including deep dyslexia and surface dyslexia, while the other was proposed by Wolf and Bowers, ${ }^{[4]}$ and including phonological deficit, rapid naming deficit and double deficits. However, these classifications cannot fit Chinese characters very well because of their distinct features, so some scholars have proposed some new subtypes according to the special features of Chinese characters. Using scores of such cognitive tasks as classification measures in cluster analyses, $\mathrm{Ho}^{[5]}$ and his colleagues proposed seven subtypes of dyslexia, including global deficit, orthographic deficit, phonological memory deficit, mild difficulty and three other subtypes involving rapid-naming-related deficits. Yang et al.[6] classified dyslexia in Chinese characters according to three subtypes by cluster analysis of 114 Chinese dyslexic children, applying the diagnostic criteria of the tenth edition of the International Classification of Diseases (ICD-10) and the Chinese reading skill diagnosis test (CRSDT), including deficit of single Chinese character recognition or decoding (21.6\%), deficit of phrases and sentences comprehension $(8.1 \%)$ and a mixed subtype $(70.3 \%)$. Also, and on the basis of cluster analysis, Chen et al.[7] defined Chinese dyslexic children according to three types by connecting reading errors with the neuropsychological processing of reading and use of the Osgood Psycholinguistic Model. The first one describes the disability of speech processing and mild memory disorders while the visual motor capacity is relatively normal. The second one is a mixed one, describing 
defects in speech comprehension, perceptive organisation, sensory and perceptive attention and memory. The third one describes the disability of visual-spatial processing, which mainly results from defects of the right hemisphere while the function of the left hemisphere is also lower than normal. Besides, $\mathrm{Wu}$ et al.[8] regarded morpheme awareness as an important element. They assigned comparable complete tests to some Chinese dyslexics and, using cluster analysis, she found seven subtypes which were relatively homogeneous and mainly resulted from cognitive defects of the linguistic layer, with each subtype containing morpheme deficits. As is known, studies of dyslexic classification are very valuable because of their heterogeneity and only when we are very familiar with them will we be able to develop successful remedies.

\section{The cerebral basis of dyslexia in Chinese characters}

The results of functional magnetic resonance imaging (fMRI) for English dyslexics suggest that there is an abnormality in the area between the two parts of the brain which provide speech cognition and speech production, which is by no means a certain area of the brain. Moreover, it is this kind of abnormality that leads to the rhyme processing deficit. ${ }^{[9-11]}$ Zhang et al.[12] came to a similar conclusion by using the magnetosphere. However, some researchers have used electro-encephalic technologies - such as functional near infrared imaging (fNIRI), single photon emission computed Tomography (SPECT), the ERP etc. - to investigate the areas of the brain which are involved in local dysfunction in dyslexic children, and they commonly argued that dysfunction of certain areas of the brain might provide the biological basis of dyslexia.[13-16] Earlier studies concerning dyslexia in Chinese characters suggested that the right hemisphere was mainly activated when reading Chinese characters, while the left hemisphere was mainly activated when reading letter languages.[1719] However, recent fMRI studies could not find evidence for hemispheric specialisation for reading different styles of calligraphy.[20-22] Some studies have suggested that although the areas activated by alphabetic language reading and Chinese character reading are in the same hemisphere, the specific locations were still obviously different. Alphabetical language reading mainly activates the left temporoparietal and occipitotemporal regions, while Chinese character reading mainly activates the left middle frontal gyrus region. ${ }^{[23-27]}$ And among these studies, Tan ${ }^{[20]}$ found that areas 9 and 46 of the left middle frontal gyrus were most activated when a participant was reading Chinese characters silently and processing them. As such, he proposed the hypothesis that the left middle frontal gyrus plays a role in coordinating and integrating when processing Chinese characters. For people whose mother tongue is English and for other alphabetical languages, the language area in the brain is located in the anterior inferior frontal gyrus of the left hemisphere (areas 45 and 4, controlling semantic analysis), the posterior inferior frontal gyrus of the left hemisphere (area 44, controlling phonetic analysis), the anterior superior temporal gyrus of the left hemisphere (areas 22 and 42, controlling letter-sound transforming) and the association area of temporal and occipital lobes (area 37, controlling the combination of sound and grapheme). In addition, some scholars have reported a brain network which can be activated both when reading Chinese characters and Chinese phonetic letters, including the inferior frontal lobe, the middle inferior part of the temporal gyrus, the superior and inferior part of the parietal lobe and the extra striate cortex. Among these structures, Chinese phonetic letter reading mainly activates the cortex of the inferior parietal lobe, the precuneus, and the central region of the temporal gyrus, while character reading mainly 
activates the left fusiform gyrus, the cuneate lobe and the posterior medial temporal lobe of both sides, and the left inferior frontal lobe and the superior part of both frontal lobes.[28] This suggests that different styles of calligraphy can lead to different brain-activated effects, so it should be taken into account when carrying out studies of dyslexia in Chinese characters. However, although this is understood, the neural basis of different kinds of dyslexia has not yet been identified clearly, and it still needs further investigation.

\section{The model of reading processing of Chinese characters}

So far, there are two major models for alphabetical language reading: the Coltheart model[29] and the Plaut model.[30] The basis of the Coltheart model is the "triple-route" view, including a lexical semantic pathway, a direct lexical pathway and a non-lexical grapheme to phoneme route. The Plaut model also assumes that semantic and orthography to phonology pathways are available for normal reading in English, but this model differs from the Coltheart model because it is based on connectionist principles of sub-symbolic processing. Moreover, it is unclear how the Coltheart model or the Plaut model would explain the oral reading of Chinese characters since both models were devised to explain the reading of alphabetical scripts. So, according to studies concerning Chinese dyslexics, Weekes et al.[31] proposed a model of the lexical processing of Chinese characters. Weekes argued that normal oral reading and writing dictation in Chinese characters can proceed via at least two bi-directional pathways: a lexical semantic pathway that allows reading and writing for meaning, and a non-semantic pathway that directly links all orthographic representations (i.e. strokes, radicals and characters) to all phonological representations (i.e. syllables, rhymes and tones). His model assumes that the lexical semantic pathway and the non-semantic pathway are functionally independent, and hence can be selectively impaired or else they will develop at different rates for early readers. Accordingly, damage to the non-semantic pathway should result in acquired deep dyslexia in Chinese characters because the input from the non-semantic pathway that is normally used to select correct phonological output is unavailable. Equally, there is no constraint on the overproduction of semantic errors via this pathway, so semantic errors are inevitable. In contrast, when the semantic pathway is damaged, patients have to use a non-semantic route and will show such symptoms as YQS and CML[32, 33] - character reading is normal while relative picture naming is difficult.

\section{Studies on the cognitive abilities of Chinese dyslexics}

Some studies of dyslexia in alphabetical languages show that the memory and attention processing ability of dyslexic children is worse than that of normal children, ${ }^{[34,35]}$ while studies of dyslexia in Chinese characters mainly focus on the visual memory processing ability. Liu et al. [36, 37] have investigated the short-term memory and long-term memory of dyslexic Chinese children. He argues that dyslexic children's visual memory processing ability is significantly worse than that of normal children and that with an increase of the material difficulty the deficit becomes more significant. When the interval is 10 minutes whether the visual materials are simple or complex - there is no significant difference in recognition ability between dyslexic and normal children. However, when the interval is one day, dyslexic children's long-term memory for simple material is normal but - in contrast - their long-term memory for complex material falls below expectations. Liu et al.[38] found that cognitive skills related to the development of Chinese and English reading 
are in accord, including memory processing ability, normal orthography of Chinese characters and detailed phonological and semantic knowledge. Chen et al.[39] found that the intelligent structure of Chinese dyslexic children is obviously unbalanced, and that there are cognitive deficits in many aspects. Besides this, McBride-Chang ${ }^{[40]}$ and his partners argue that dyslexic children perform significantly worse in tone detection, morphological awareness and Chinese word recognition. In a word, there are only a few studies concerning the cognitive abilities of Chinese dyslexics. What is more, since some studies suggest that the left middle frontal gyrus region plays an important role in Chinese character reading, future studies should focus more on executive function in dyslexia.

\section{Saccadic studies of dyslexia in Chinese characters}

One piece of evidence which can document the close relationship between developmental dyslexia and saccade is the study of deaf developmental dyslexics.[41] Experiments showed that there are defects in the megacells of these patients. As such, in visual processing, their contrast sensitivity is abnormal and so low contrast stimulus responses will be delayed. As for developmental dyslexics, their ability to control saccade is weakened - the saccadic model is abnormal and there is visual confusion. What is more, they see letters as fleeting and mixing together, and their capability of describing the visual shapes of letters is weak. In recent years, domestic scholars have been paying attention to this kind of study. For example, using a saccadic study, Li et al[42] found that when Chinese dyslexic children read, their saccadic style is abnormal, displaying a longer than average fixation time, smaller saccadic amplitude, chaotic saccadic locus, a lack of a sense of a plan, a strategy and organization and distractedness. They argue that a defect of picture memory and processing ability is not the major characteristic of Chinese dyslexic children. However, when the picture background is complex, dyslexic children's attention span is more limited and their visual fixation efficiency goes down. ${ }^{[43]}$ Huang et al.[44] found that there is a deficiency in quick naming for Chinese dyslexic children and that there is an abnormal saccadic style associated with it, suggesting that it may reflect a defect in visual space and visual attention. In addition, Zhang et al.[45] investigated normal readers, burdensome readers and disabled readers and watched their saccadic characteristics when reading Chinese characters. They found that the second type of readers' timeline feeding was obviously prolonged and the number of returning watching increased. While the third type of readers' saccadic locus was confused, the returning watching efficiency was higher and the boundaries between lines could hardly be distinguished.

\section{Erp studies on dyslexia in Chinese characters}

Studies of dyslexia in alphabetical languages with ERP have demonstrated the special characteristics of basic perceptive and language processing, for example, the amplitude of P300 tends to decrease and its latency tends to be delayed. What is more, P300 can easily have no response or a false response towards the stimuli of multiple goals and non-goals. Indeed, Sha et al. ${ }^{[46]}$ concluded this in a review. Jing et al. ${ }^{[47]}$ investigated the characteristics of ERP in Chinese dyslexic children under the conditions of the continuous performance test (CPT) - i.e. using the ERP technique with CPT conditions, such as semantics, direction and pitch identification - to test 16 Chinese dyslexic boys and their matched normal boys. Moreover, a comparative study was conducted to analyse these indicators of accuracy, reaction time, false alarm, wave amplitude and latency between the two groups. The results 
show that among the three kinds of identification tests, Chinese dyslexic children had lower accuracy in pitch identification $(65.4 \pm 15.9$ to $78.5 \pm 12.6)$ and lower reaction speed (557.0 \pm 97.8 $\mathrm{ms}$ to $493.0 \pm 47.8 \mathrm{~ms})$ as compared to the control group $(\mathrm{P}<0.0105)$. The false alarm rate was much higher in $\mathrm{RD}$ children than in the control group, with unattended-high stimulation $(1.1 \pm 0.7 \%$ to $0.6 \pm 0.3 \%$; $<<0.05)$. Moreover, the P300 amplitude decreased with direction $(20.8 \pm 7.3 \mu \mathrm{v}$ to $27.7 \pm 8.3 \mu \mathrm{v})$ and pitch $(9.1 \pm 4.3 \mu \mathrm{v}$ to $14.6 \pm 8.3 \mu \mathrm{v} ; \mathrm{P}<0.05)$. In addition, there was a latency delay in pitch $(571 \pm 78 \mathrm{~ms}$ to $512 \pm 62 \mathrm{~ms})$ and semantic cognition processing negativity ( $\mathrm{Nd}$ of $398 \pm 76 \mathrm{~ms}$ to $342 \pm 67 \mathrm{~ms}$; pitch $\mathrm{Nd}$ of $373 \pm 56 \mathrm{~ms}$ to $327 \pm 53 \mathrm{~ms} ; \mathrm{P}<0.05$ ). These results suggest that there was a defect in the selective attention of dyslexic children, which suggests a relationship between dysfunction of the frontal-basal ganglia circle and dyslexia. The ERP combined with CPT was much better than that with single target stimulation in indicating children's cognitive characteristics. Besides this, Zhou et al. have done an ERP study using a sentence reading task. The crucial manipulation was on the sentence-final two character compound words, which were either correct or incorrect. For the incorrect compounds, the second characters of the base words were replaced by homophonically or orthographically similar characters. It was found that, for the normal controls, the orthographic and phonological mismatches elicited more negative ERP responses, relative to the baseline, over a relatively long time-period (including the time windows for P200 and N400) at the central-posterior scalp regions. In contrast, the dyslexic children - in general - showed no differences between experimental conditions for P200 and N400. In addition, one ERP study showed that the main characteristics of dyslexic patients' auditory wave shape was a marked delay of latency and an obvious decrease of amplitude.[49] Accordingly, the ERP is a method for understanding the auditory processing of dyslexic children from a more intuitional point of view.

\section{Diagnosis, assessment and intervention of dyslexia in Chinese characters in children}

There are several diagnosis and assessment instruments currently used in China, such as the Chinese edition of "the Pupil Rating Scale Revised-Screening for Learning Disabilities (PRS)" - translated and appraised by JING and his colleagues[50] - the "CRSDT" developed by Yang et al.[51] and the "Revised Mr. Tsui Reading Test" by Liu et al..52] since the 1980s. Wu et al.[53] established "The Dyslexia Checklist for Chinese Children (DCCC)", which was based on the definition and diagnostic criteria of dyslexia in the tenth edition of "ICD-10", and the "Diagnostic and Statistical Manual: Mental Disorder" Release 4 (DSM-IV). In addition, Gai[54] produced "The Chinese Character Learning Test (CCLD)", which not only reflects the total amount of children's Chinese character recognition statically, but also reflects the capability of children's Chinese character recognition dynamically. Thus, it contributed a complementary role in the diagnosis of dyslexia in Chinese characters in children. Nevertheless, there are no unified criteria for diagnosing and assessing dyslexia in Chinese characters, which undoubtedly is a significant problem for research into dyslexia in Chinese characters at present. Therefore, developing and utilising a unified scale for screening dyslexia in Chinese characters in children is one of the topics that should be explored by professionals in children's health, psychology and education systems.

Intervention for English dyslexic children is mature, and a complete scientific intervention system has been created, including two major methods: namely, phonology-based practice and practice based on sensory perception processing. For Chinese dyslexic patients, Peng et al.[55] proposed combining phonological awareness and semanteme awareness in 
intervention and carrying it out as early as possible. However, there is no widely accepted theory or standard for intervention in dyslexia in Chinese characters and, what is worse, there is no specific evidence.

\section{Perspectives}

Over the last ten years, great progress has been made in the number and level of studies into dyslexia in Chinese characters, accumulating a lot of information for the theoretical study of dyslexia, providing a theoretical basis for the prevention and treatment of dyslexia. However, there are still many problems and shortcomings. For example, there are few studies on the physiological basis, brain function and genetics - as well as other aspects - of dyslexia in Chinese characters. Moreover, although basic research into dyslexia has made some achievements and accumulated a great deal of information, current research into its application is still far behind the basic research. Therefore, future studies into dyslexia in Chinese characters should focus more on these areas.

\section{References}

[1] Sally E, Shay Witz, MD. Dyslexia. N Eng 1 J Med, 1998, 338: 307-312.

[2] Stevenson HW, Stigler J W, Lucker GW, et al. Reading disabilities: The case of Chinese, Japanese and English. Child Dev, 1982, 53: 1164-1181.

[3] Castles A, Coltheart M. Varieties of developmental dyslexia. Cognition, 1993; 47: 149180.

[4] Wolf M, Bowers PG. The double-deficit hypothesis for the developmental dyslexia. J Educ Psychol, 1999; 91: 415-438.

[5] Ho CS, Chan DW, Lee SH, Tsang SM, Luan VH. Cognitive profiling and preliminary subtyping in Chinese developmental dyslexia. Cognition, 2004; 91: 43-75.

[6] Yang ZW, Gong YX. Development of Chinese reading skill diagnostic test: reliability and validity. Chin J Clin Psychol (Chin), 1997; 5: 158-161.

[7] Chen HB, Yang ZW, Tang XL. Cognitive function of Chinese children with reading disorder [I]. Chin Ment Health J (Chin), 2001; 16: 49-51.

[8] Wu SN, Shu HN. The subtype study of developmental dyslexia. Chin J Spec Educ (Chin), 2007; 4: 29-34.

[9] Galaburda AM. Neuroanatomic basis of developmental dyslexia. Neurol Clin, 1993; 11: 161-173.

[10] Hiemenz JR, Hynd GW. Sulcal/gyral pattern morphology of the perisylvian language region in developmental dyslexia. Brain Lang, 2000; 74: 113-133.

[11] Paulesu E, Frith U, Snowling M, Gallagher A, Morton J, Frackowiak RS, et al. Is developmental dyslexia a disconnection syndrome? Evidence from PET scanning. Brain, 1996; 119: 143-157.

[12] Zhang WB. Functional neuroradiology-magnetoence-phalography evaluation of language function. Int J Med Radiol (Chin), 2002; 25: 212-215.

[13] Wu YG, Su JZ, He JJ, Yang ZW, Liu GF. The correlative analysis between CBF measured by SPECT and Chinese reading test in childhood reading disorder. Chin J Nucl Med (Chin), 2002; 2: 13-15.

[14] Chen HB, Wang DB, Yang ZW. SPECT research on Chinese children with reading disorder. J Yunyang Med Coll (Chin), 2003; 22: 210-212.

[15] Wu HR, Yao B. Study on the mechanism of visual coding and language activities of children with Chinese dyslexia by fNIRI. Chin J Sch Health (Chin), 2004; 25: 4-7. 
[16] Wu HR, Song RR. The fNIRI study on regional cerebral blood oxygenation changes during cognition tasks of Chinese dyslexic children. Chin J Clin Psychol (Chin), 2004; 12: 383-385.

[17] Fang SP. Morphological properties and the Chinese character- word difference in laterality patterns. J Exp Psychol: Hum Percept Performance, 1997; 23: 1439-1453.

[18] Cheng CM, Yang MJ. Lateralization in the visual perception of Chinese characters and words. Brain Lang, 1986; 36: 669-689.

[19] Naeser MA, Chan SW. Case study of a Chinese aphasic with the Boston diagnostic aphasia exam. Neuropsychologia, 1980; 18: 389-410.

[20] Tan LH, Spinks JA, Gao JH, Liu HJ, Perfetti CA, Xiong J, et al. Brain activation in the processing of Chinese characters and words: a functional MRI study. Hum Brain Mapp, 2000; 10: 16-27.

[21] Chee MW, Caplan D, Soon CS, Sriram N, Tan EW, Thiel T, et al. Processing of visually presented sentences in Mandarin and English studied with fMRI. Neuron, 1999; 23: 127-137.

[22] Chee M, Tan E, Thiel T. Mandarin and English single word processing studies with functional magnetic resonance imaging. J Neurosci, 1999; 19: 3050-3056.

[23] Shaywitz BA, Shaywitz SE, Pugh KR, Fulbright RK, Mencl WE, Constable RT. The neurobiology of dyslexia. Clin Neurosci Res, 2002; 1: 291-299.

[24] Lei M, Liu HL, Jin H, Yang YL. Brain activation during semantic judgment of Chinese sentences: a functional MRI study. Huma Brain Mapp, 2005; 24: 305-312.

[25] Perfetti CA, Tan LH, Siok WT. Brain-behavior relations in reading and dyslexia: implications of Chinese results. Brain Lang, 2006; 98: 344-346.

[26] Siok WT, Niu Z, Jin Z, Perfetti CA, Tan LH. A structural-functional basis for dyslexia in the cortex of Chinese readers. Proc Natl Acad Sci USA, 2008; 105: 5561-5566.

[27] Siok WT, Perfetti CA, Jin Z, Tan LH. Biological abnormality of impaired reading is constrained by culture. Nature, 2004; 431: 71-76.

[28] Chen YP, FU SM, Iversen SD, Smith SM, Matthews PM. Testing for dual brain processing routes in reading: a direct contrast of Chinese character and pinyin reading using Fmri. J Cogn Neurosci, 2002; 14: 1088-1098.

[29] Coltheart M, Rastle K, Perry C, Langdon R, Ziegler J. DRC: a dual route cascaded model of visual word recognition and reading aloud. Psychol Rev, 2001; 108: 204-206.

[30] Plaut DC, McClelland JL, Seidenberg MS, Patterson K. Understanding normal and impaired word reading: computational principles in quasi-regular domains. Psychol Rev, 1996; 103: 56-115.

[31] Weekes BS, Chen MJ, Yin WG. Anomia without dyslexia in Chinese. Neurocase, 1997; 3: 51-60.

[32] Weekes BS, Chen MJ, Yin WG. Anomia without dyslexia in Chinese. Neurocase, 1997; 60: 140-143.

[33] Law SP, Orr BA. Case study of acquired dyslexia and dysgraphia in Cantonese: evidence for nonsenmantic pathways for reading and writing. Cogn Neuropsychol, 2001; 18: 729-748.

[34] Facoetti A, Lorusso ML, Paganoni P, Umiltà C, Mascetti GG. The role of visuospatial attention in developmental dyslexia. Brain Res Cogn Brain Res, 2003; 36: 109-123.

[35] Vellutino FR, Steger JA, DeSdtto L, Phillips F. Immediate and delayed recognition of visual stimuli in poor and normal readers. J Exp Child Psycho1, 1985; 19: 223-232. 
[36] Liu XP, Du WZ, Wang B, Wu SW. Study on characteristics of visual short-term memory ability of Chinese-speaking dyslexic children. Chin J Spec Educ (Chin), 2005; 12: 4855.

[37] Wang B, Liu XP, Liu XQ, Lin M. Study on characteristics of visual long-term memory ability of Chinese-speaking dyslexic children. Chin J Spec Educ (Chin), 2006; 3: 69-73.

[38] Liu WL, Liu XP. Cognitive skills related to reading development. Adv Psychol Sci (Chin), 2006; 14: 665-674.

[39] Chen HB, Yang ZW, Tang XL. Cognitive function of Chinese children with reading disorder. Chin Ment Health J (Chin), 2002; 16: 49-51.

[40] McBride-Chang C, Lam F, Lam C, Doo S, Wong SW, Chow YY. Word recognition and cognitive profiles of Chinese pre-school children at risk for dyslexia through language delay or familial history of dyslexia. J Child Psychol Psychiatry, 2008; 49: 211-218.

[41] Samar VJ, Parasnis I, Berent GP. Deaf poor readers' pattern reversal visual evoked potentials suggest magnocellular system deficits: implications for diagnostic neuroimaging of dyslexia in deaf individuals. Brain Lang, 2002: 21-44.

[42] Li XH, Jing J, Zou XB, Huang X, Cheng XB, Yang BR. Experiment studies of eye movement of Chinese children with reading disorder when reading Chinese article. Chin Ment Health J (Chin), 2007; 6: 362-364.

[43] Li XH, Jing J, Yang BR, Yang SY, Wang QX, Chen XB. An experiment study on the eye movement of reading disorder children during apperceiving pictures. Chin Ment Health J (Chin), 2007; 1: 6-9.

[44] Huang X, Wu HR, Jing J, Zou XB, Wang ML, Li XH. Characteristics of Eye movements of Chinese children with specific reading disability in rapid naming task. Chin Ment Health J (Chin), 2007; 6: 358-361.

[45] Zhang ZT, Peng DL, Zhang BY. The saccades and fixation when reading. Psychological Science (Chin), 1993; 16: 309-311.

[46] Sha SY, Zhou XL, Meng XZ. A ERP study of developmental dyslexia. Adv Psychol Sci (Chin), 2003; 11: 141-146.

[47] Jing J, Morinaga R, Zhang XZ, Huang X, Chen XB. The event-related potential characteristics of reading disabilities in children under condition of continuous performance test. Chin J Prev Med (Chin), 2001; 2: 92-95.

[48] Meng X, Tian X, Jian J, Zhou X. Orthographic and phonological processing in Chinese dyslexic children: an ERP study on sentence reading. Brain Res, 2007; 79: 119-130.

[49] He SX, Yin WG, Yang ZW. Chinese developmental dyslexia: audio-visual integration ERP study. Chin J Behav Med (Chin), 2006; 15: 117-119.

[50] Jing J, Morinagn R, Huang X, Li XH. The revision and appraisal of the pupil rating scale revised-screening for learning disorder. Chin J Child Health Care (Chin), 1998; 3: 197-200.

[51] Yang ZW. The initial authorization of diagnostic test of Chinese reading skills. Chin J Clin Psychol (Chin), 1997; 5: 158-161.

[52] Liu J, Wang YF, Shen YC. The testing report of the revised reading test. Chin Ment Health J (Chin), 1997; 11: 264-266.

[53] Wu HR, Song RR, Yao B. The establishment of dyslexia checklist for Chinese children. Chin J School Health (Chin), 2006; 3: 189-190.

[54] Gai XF, Yang FF. The preparation of test for literacy status of Chinese children with dyslexia. Chin J Spec Educ (Chin), 2006; 11: 58-63.

[55] Peng H, Shu H. Developmental dyslexia and early phonological training. Chin J Spec Educ (Chin), 2001; 1: 39-43. 


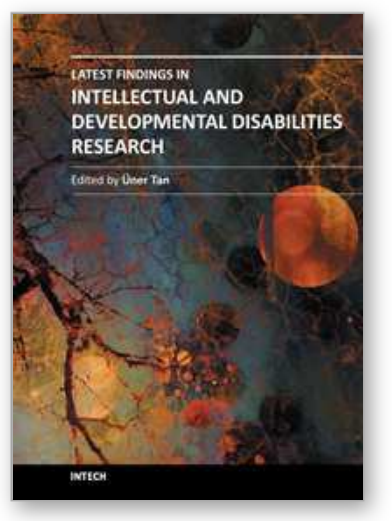

\author{
Latest Findings in Intellectual and Developmental Disabilities \\ Research \\ Edited by Prof. Uner Tan
}

ISBN 978-953-307-865-6

Hard cover, 404 pages

Publisher InTech

Published online 15, February, 2012

Published in print edition February, 2012

Intellectual and Developmental Disabilities presents reports on a wide range of areas in the field of neurological and intellectual disability, including habitual human quadrupedal locomotion with associated cognitive disabilities, Fragile $X$ syndrome, autism spectrum disorders, Down syndrome, and intellectual developmental disability among children in an African setting. Studies are presented from researchers around the world, looking at aspects as wide-ranging as the genetics behind the conditions to new and innovative therapeutic approaches.

\title{
How to reference
}

In order to correctly reference this scholarly work, feel free to copy and paste the following:

Jin Jing, Guifeng Xu, Xiuhong Li and Xu Huang (2012). Studies Related to Dyslexia in Chinese Characters, Latest Findings in Intellectual and Developmental Disabilities Research, Prof. Uner Tan (Ed.), ISBN: 978-953307-865-6, InTech, Available from: http://www.intechopen.com/books/latest-findings-in-intellectual-anddevelopmental-disabilities-research/studies-related-to-dyslexia-in-chinese-characters

\section{INTECH}

open science | open minds

\section{InTech Europe}

University Campus STeP Ri

Slavka Krautzeka 83/A

51000 Rijeka, Croatia

Phone: +385 (51) 770447

Fax: +385 (51) 686166

www.intechopen.com

\section{InTech China}

Unit 405, Office Block, Hotel Equatorial Shanghai

No.65, Yan An Road (West), Shanghai, 200040, China

中国上海市延安西路65号上海国际贵都大饭店办公楼 405 单元

Phone: +86-21-62489820

Fax: +86-21-62489821 
(C) 2012 The Author(s). Licensee IntechOpen. This is an open access article distributed under the terms of the Creative Commons Attribution 3.0 License, which permits unrestricted use, distribution, and reproduction in any medium, provided the original work is properly cited. 